\title{
La opinión publicada en la prensa de México (Columna, artículo y editorial)
}

\section{The opinion published in the press in Mexico (Column, article and editorial)}

\author{
Lizy Navarro Zamora \\ Universidad Autónoma de San Luis Potosí (México) \\ lizy@uaslp.mx
}

Recibido: 15 de Octubre de 2010 Aceptado: 1 de Diciembre de 2010

\section{Resumen}

El presente trabajo es un estudio de los géneros de opinión en la prensa mexicana. Se realizó una investigación de la columna, el artículo y la editorial (5848 unidades redaccionales). Qué preocupa, de qué se habla, modos de hacerlo, debates e ideologías. El artículo, la columna y el editorial son una representación muy fiel de como es una sociedad y de cuáles son los temas que le preocupan y ocupan.

\section{Abstract}

The present study is about the gender opinion in the mexican press (about 5848 papers). This investigation was about the column, the article and the editorial. What problem? What topics?, moods, discussions and ideologist. The column, the article and the editorial are a representation of the society and the topics that worry and occupy.

Palabras Clave: periodismo, artículo, columna, editorial, opinión.

Key Words: journalism, article, column, editorial, opinion. 


\section{Planteamiento y ubicación del problema.}

El presente texto es el resultado del análisis realizado a la opinión pública generada en la prensa mexicana. Se escogió este medio porque en él se desarrollan más profundamente los géneros de opinión y es el espacio que tiene una presencia significativa entre quienes ostentan los diferentes poderes. El artículo, la columna y el editorial son una representación muy fiel de como es una sociedad, de cuáles son los temas que le preocupan y ocupan y de quienes son los líderes de opinión.

El periodismo nació como un periodismo ideologizante que se desarrolló profundamente en el siglo XVIII y XIX. En aquel momento lo que más se buscaba era precisamente el convencimiento de las ideas, la defensa de una postura. Los textos de opinión fueron elementos esenciales en los movimientos ideológicos y políticos de la época. El periodismo era de opinión y no informativo ni interpretativo.

En el mundo actual está comprobado que la profesión periodística y su papel de organizadora, informadora y orientadora de la realidad social contribuyen esencialmente al desarrollo o retroceso del proceso democrático de todo país, región o comunidad. Es esta actividad la que permite ensanchar la libertad de los hombres y contribuir al desarrollo humano equilibrando los poderes decretados o de facto, sobre todo porque los media son instituciones de innegable personalidad política.

La libertad de expresión ideológica que se ejerce en los diversos medios de comunicación permite el enriquecimiento de la sociedad. Esta profesión que produce mensajes periodísticos tiene máximas éticas como Los hechos son sagrados y las opiniones son libres. La división en géneros periodísticos no deviene de un principio académico, sino de uno ético, organizar los diferentes contenidos para que el receptor de los mensajes (lector, radioescucha, televidente o usuario) decodifique la información sin engaños.

En la radio y en la televisión mexicana también se desarrolla el género de opinión, programas como Primer Plano de Canal 11 en México presenta una serie de columnas de los periodistas que allí participan. Sin embargo, sólo la élite académica, política y cultural es quien consume dichos comentarios.

Los columnistas o articulistas de prensa que simultáneamente presentan su opinión en la radio, en la televisión y en la prensa, refuerzan efectivamente su opinión e inducen su postura. Los periodistas son los representantes en los cuales la sociedad delega una responsabilidad de ser mediadores de los conflictos ideológicos y de transmitir ideas, 
creencias, conocimientos y opiniones de la sociedad. Es precisamente en estos espacios donde se manifiestan de manera explícita las ideologías del autor.

La opinión es una labor social de los articulistas y columnistas, pero también del propio medio de comunicación. El editorial, como género de opinión independiente de la columna y del artículo, define la postura que tiene el medio sobre asuntos que preocupan, ocupan a la sociedad, y más aún, de aquellos que la sociedad no los considera importantes porque no se tiene una visión integral de lo que sucede. A través del editorial la empresa periodística establece una postura, por ello su estudio es significativo.

Los llamados géneros de opinión son la guía y la pauta de los temas que deben de importar e interesar al país, pero también son espacios que los círculos en el poder aprovechan para ideologizar a otros grupos.

Los géneros de opinión orientan a la sociedad y a las élites de lo que pasa, también impulsan un debate de los temas considerados de interés social, política y económica. La educación, la contextualización y la instrucción son objetivos fundamentales de los medios, sin embargo, la realidad es que los géneros de opinión no son leídos por la mayoría de la población.

Estos textos manifiestan como es México en sus manifestaciones ideológicas, en las bases de sus principios y valores democráticos, y en sus preocupaciones manifestadas. La opinión pública "publicada" en la prensa es la imagen y preocupación de la sociedad mexicana en un momento determinado.

\section{Metodología.}

Esta investigación se basó en las siguientes acotaciones.

- Acotación temporal: Los periódicos de los meses de diciembre del 2008, enero, febrero y marzo 2009.

- Acotación espacial: Se estudiaron aquellos diarios cuya tirada es considerada nacional y su cobertura alcanza entidades federativas como la de San Luis Potosí. Los artículos y las columnas son las correspondientes a las tradicionales páginas de Opinión y a la primera Sección o Nacional.

-Acotación temática: los periódicos impresos analizados fueron La Jornada, El Universal, Excelsior, Milenio, El financiero y Reforma. En el estudio consideramos 
nacionales a estos medios bajo la connotación de que sus informaciones tienen repercusiones en el ámbito geopolítico del país.

Los espacios de opinión no considerados para la investigación fueron como El Lector Escribe, del periódico Reforma, debido a que los lectores son quienes colaboran. En La Jornada está el Correo ilustrado, tiene una sección de Yo lector; en El Universal el espacio de La Voz del Lector. En Milenio se encuentra la columna Lectores de Milenio y así en cada uno de los medios analizados hay un espacio para que el lector escriba. En esta investigación el texto estudiado fue el que emite un periodista o colaborador que conoce ex profeso la importancia y significado de estos escritos.

Análisis de contenido: se realizó un análisis de contenido a cada uno de los textos del corpus con el objetivo de conocer elementos esenciales como los códigos, los contenidos y las prácticas discursivas.

\section{Método de trabajo}

Recopilación. Durante el mes de diciembre del 2008 y los meses de enero, febrero y marzo se seleccionaron los artículos, columnas y editoriales de las secciones y de los periódicos antes mencionados. Menos del $2 \%$ del total de los periódicos no se analizaron debido a que ese día se presentó un problema de distribución en la entidad.

Censo: Elaboración de un censo de articulistas de periódicos: quiénes son y representación social (trabajo que desarrollan, campo de conocimiento que representan y organismo al que pertenecen). Este censo está ordenado de tal forma que se puede considerar por relación de artículos por mes, día, autor y periódico; relación de artículos por autor, título, día, mes y periódico; relación total de autores por nombre completo, nombre de firma y representación social; relación de columnistas por nombre completo, firma, profesión, periódico y número de artículos publicados.

Para conocer esta imagen que presenta la opinión pública se realizó el estudio de 3108 columnas, 2533 artículos y 207 editoriales del mes de diciembre del 2008 y de enero, febrero y marzo del 2009. Los periódicos analizados fueron el Excelsior, La Jornada, El Universal, Reforma, Milenio y El Financiero. El estudio se aplicó al medio impreso debido a que las versiones en Internet no contienen todas las columnas y artículos y no están organizadas y publicadas como en el medio impreso. 
En el análisis de estos medios se consideraron variables como el género del autor, los temas, los subtemas, el marco temático, las tesis presentadas y los argumentos, entre otros elementos. En el marco temático se presentaron las siguientes variables: a) Crimen organizado, narcotráfico y corrupción; b) crisis económica, finanzas, economía y presupuesto del gobierno; c) partidos políticos y elecciones; d) gobierno de Felipe Calderón y Secretarías de Estado; e) Política exterior y temas internacionales; f) otros.

\section{Discusión de Resultados}

Los resultados se expondrán de la siguiente manera, en primer lugar lo que entendemos por cada una de las temáticas, después profundizar en la columna, el artículo y el editorial, para finalmente dar detalles de algunos elementos significativos como el género y la interactividad

\subsection{Crimen organizado, narcotráfico y corrupción.}

Cuando se inició esta investigación se pensó que precisamente el tema de narcotráfico y crimen organizado serían los que más se tratarían y analizaría en los textos de opinión, sobre todo porque los espacios informativos publican diariamente las ejecuciones y actividades del crimen organizado. Si el gobierno mexicano no puede establecer estrategias adecuadas y un verdadero proyecto de solución, los articulistas, columnistas y el editorial de los medios son los espacios que deben clarificar los antecedentes, situación actual y proyección de esta problemática.

\subsection{Crisis económica, finanzas, economía y presupuesto del gobierno:}

En la macroestructura textual se determinó este código debido a que desde el 2008 hasta la actualidad diversas naciones, entre ellas México, presentan el problema de la crisis. Ante un problema de gran magnitud es importante que en el género de opinión se evalúen las propuestas, los avances y los resultados. El ciudadano difícilmente tiene el espacio y los elementos para realizar una interpretación adecuada de la situación actual.

\subsection{Partidos políticos y elecciones:}

El periodismo se ha definido como el perro guardián "watch-dog". En una democracia que se encuentra en proceso es precisamente el género de opinión a través del artículo, columna y editorial quien puede guiar, interpretar y enjuiciar los procesos electorales generales y los procesos internos de los partidos políticos. El periodista no tiene el fuero común de los 
servidores públicos, ni la posibilidad legal para sancionar, pero sí el prestigio profesional para presentar una visión clara.

También aquí entra la apuesta de los partidos políticos que a través de los articulistas tratan de convencer de sus posturas ideológicas, económicas, sociales y culturales. Como ejemplos tenemos artículos del ex presidente Carlos Salinas de Gortari, del arzobispo primado Norberto Rivera Carrera, de presidentes de Partidos Políticos, entre otros. Los autores buscan convencer a sus lectores de su apuesta y su postura. Más que presentar una opinión crítica, proponen y exponen de manera disfrazada sus propios intereses.

\subsection{Gobierno de Felipe Calderón y Secretarías de Estado.}

Este es otro tema en el cual enfocamos la investigación: las apuestas y propuestas tanto del presidente de la República como de sus secretarios de estado. Artículos y columnas claramente enfocadas a los intereses gubernamentales, frente a otros que hacen un análisis crítico de las propuestas de estado.

\subsection{Política exterior y temas internacionales.}

Ante la globalización política y sobre todo económica se consideró como uno de los elementos fundamentales los temas internacionales 0 aquellos asuntos nacionales relacionados con la política exterior. La toma de posesión en enero del presidente de Estados Unidos Barack Obama fue lo que se presentó como uno de los grandes temas a considerar.

Otros temas: En el apartado otros se incluyeron los textos periodísticos que no podían englobarse en ninguna de las anteriores posibilidades. Cabe aclarar que en una parte de ellos se encontró que algunos columnistas o articulistas desperdician su espacio con temas personales que no tienen repercusión en la agenda social.

\section{Columna}

José Luis Martínez Albertos define la columna como "El comentario es un artículo razonador, orientador, analítico, enjuiciativo, valorativo -según los casos- con una finalidad idéntica a la del editorial." (1998:372). Como completa Luisa Santamaría "La columna vale tanto como la que valga su firma" (1990:53). 
En la columna son evidente estas funciones: 1) quienes transmiten las ideologías y son ejecutores de campañas políticas, 2) quienes combaten consignas ideológicas y seudorealidades, 3) explican temas concretos relacionados con la agenda periodística, 4) participan en el debate social.

El texto de la columna responde en su mayoría a la línea ideológica del medio en el cual se trabaja. Son breves y poco profundas. Con la imagen que tiene el columnista ya reconocida por el lector es necesario que se aprovechen dichos textos, no sólo para pasar un rato relajado, sino para que se proyecten análisis profundos y argumentados en los cuales el pensamiento racional sea el que prevalezca.

Las dos características básicas son la periodicidad y el nombre fijo. En los seis medios se detectaron 152 columnas distintas de un total de 3098 textos analizados. En su diseño la columna ha evolucionado, en la actualidad vemos columnas que tienen la imagen del autor o la autora. En este texto, a diferencia del artículo, el periodista es quien prevalece como emisor del mensaje (Gráfica 1), esto se debe a que la periodicidad es más constante y parte de su trabajo remunerativo está precisamente en la elaboración de las columnas.

\section{Gráfica 1}

Perfil del columnista

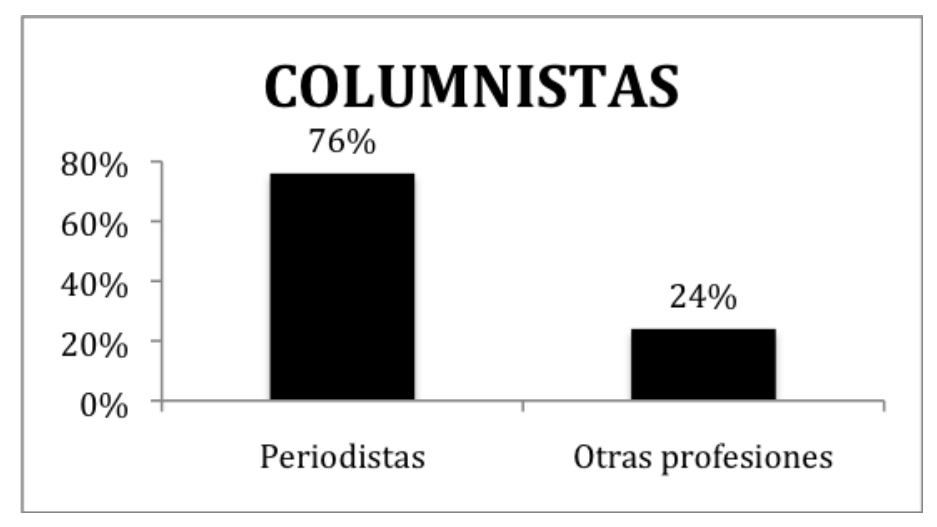

Elaboración propia

En este análisis observamos columnas con diversidad en su presentación y análisis, desde Astillero y Clase Política que son textos donde se tratan varios temas de interés y considerados significativos para el autor, hasta aquellos donde se aborda un tema con 
profundidad y que sería comparable a un artículo, con la diferencia de que aparece en un espacio con nombre fijo.

Hay columnas que se presentan diariamente como la de Razones, frente a otras que tienen periodicidad quincenal o mensual. También hay columnas que son propiedad del autor como la de Plan B de Lydia Cacho u otras donde cambia quien escribe y se mantiene el nombre como en el caso Desde Cabina. También hay textos que se publican diariamente como el de Frente Políticos que no firma alguien.

En los temas y debates de las columnas (Cuadro 1) se presentó la siguiente constante. Durante el período analizado prevaleció el tema economía, seguido por el de temas internacionales y crimen organizado. Son precisamente estos problemas los que más aquejan al país y crean la conciencia en la élite del poder. Tener una visión clara, de análisis y comentario profundo, es fundamental para el lector.

En un $2 \%$ del $16 \%$ del total de las columnas que se quedaron en Otros, podemos decir que se desperdició el espacio de publicación. El columnista no sólo habló de temas intrascendentes para el país y cuestiones que atañen más a su vida privada. También observamos que hay columnas muy cortas en su extensión frente a otras muy largas. Aún cuando en pocas líneas se puede expresar profundidad en el pensamiento, lo cierto es que en algunos de ellos es evidente que no se toman el tiempo de realizar el análisis profundo o comentarios serios. Las columnas disminuyeron en el mes de diciembre debido a que los autores salen de vacaciones en dicho periodo.

\section{Cuadro 1}

Presencia temática en la columna.

\begin{tabular}{|c|c|}
\hline Temas y debates en las columnas & $\%$ \\
\hline Crimen organizado, narcotráfico, impunidad y corrupción & $16 \%$ \\
\hline Crisis, economía, finanzas & $26 \%$ \\
\hline Partidos políticos y elecciones & $4 \%$ \\
\hline Gobierno de Felipe Calderón y secretarios de estado & $15 \%$ \\
\hline Política exterior y temas internacionales & $22 \%$ \\
\hline Otros & $16 \%$ \\
\hline
\end{tabular}

Elaboración propia. 
Hay columnas en el periódico Reforma como la de Templo Mayor en la cual se abordan varias noticias y opiniones sobre diferentes temas y son firmadas con un seudónimo. Es importante precisar que los textos que se presentan como columnas en el Reforma aparecen como artículos en el Norte. Esto no es recomendable ya que cada género periodístico tiene una finalidad y una deontología.

No se debe olvidar que los columnistas presentan de manera permanente y periódica la riqueza en la diversidad de pensamiento y a su vez en las propuestas de construcción. Para un país que tiene tantos temas de preocupación, es necesario que de manera permanente alguien clarifique (columnistas) dichas situaciones a través de los textos periodísticos.

\section{Artículo}

Los diarios se presentan como mediadores en la construcción de la realidad cultural, ideológica y política. Aportan ideas cuando se presentan conflictos y construyen la posibilidad de una realidad. La opinión es parte del deber ser de los periodistas, siempre y cuando sea una opinión presentada como tal.

María Jesús Casals Carro afirma que "El artículo es la forma característica del periodismo de opinión y es, en todos los casos, un discurso expresivo. Atendiendo a su estructura externa, los artículos pueden ser inductivos o deductivos". (2000:150). Mientras que Ángel Benito dice que el Artículo es "En sentido estricto, texto firmado, no directamente informativo, en el que su autor comenta, explica y toma posición sobre cualquier asunto de interés general, manteniendo su opinión personal" (2001:20).

En el espacio del artículo encontramos desde investigadores de universidades de prestigio quienes son los que tienen la capacidad de dar una mejor orientación por la profundidad de sus investigaciones, hasta líderes políticos, ex secretarios de estado, ex candidatos a puestos de elección. El artículo en México se ha convertido en un texto de presencia ideológica y de estrategia para litigar en los medios de comunicación.

Ortega y Gasset fue quien en su momento afirmó que los filósofos escribían precisamente en los periódicos. Esta opinión la desarrolló cuando en el mundo y en México se realizaba un periodismo ideologizante. En el estudio se observó que el articulista es un escritor más o menos ocasional en el periódico y no tiene una periodicidad fija aunque escriba con frecuencia. En el total de 2533 artículos se presentaron 483 autores quienes generaron su opinión pública y proceden de diversas profesiones, sin una unificación clara (Gráfico 1). Los 
articulistas no son periodistas de ejercicio, sino profesionistas que ejercen este género de manera independiente a su actividad económica. Muy similar de cuando empezó el periodismo en el siglo XIX.

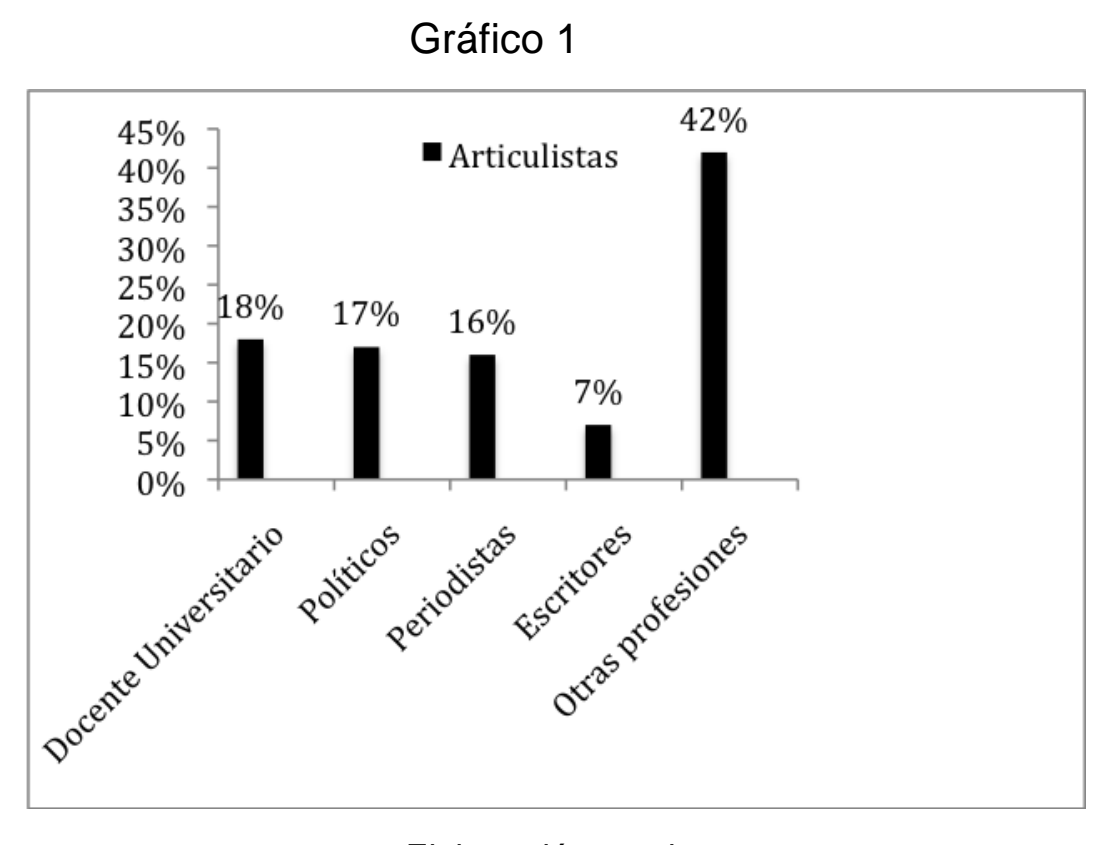

Elaboración propia.

Articulistas como Alejandro Gertz Manero, el escritor Carlos Fuentes, el ex presidente Carlos Salinas de Gortari, el ex recetario de la ONU Kofi A. Annan, investigadores de la UNAM, son quienes invaden estas páginas. Estos textos no siempre son escritos por quienes han recibido la formación de periodistas, sino por líderes de espacios de poder.

En más del $96 \%$ los artículos de opinión presentan una postura racional, argumentada, con un método deductivo en la presentación de sus ideas y menos ad populum. El problema sin lugar a duda es que el consumo de estos textos no lo hace la mayoría de la población, sino la élite del poder. Por ejemplo periódicos como El Universal titulan colaboración especial a un artículo del ex presidente Carlos salinas de Gortari igual que en Milenio.

Como observamos en los resultados (Cuadro 2) los temas que prevalecieron fueron los de crimen organizado, otros y economía. Otro de los temas abordados fue el de la toma de posesión del presidente de Estados Unidos, Barack Obama, sin embargo en más del $70 \%$ 
de estos artículos no hubo propuesta sobre cómo se debe construir la relación Estados Unidos-México.

\section{Cuadro 2}

Temas y debates en los artículos.

\begin{tabular}{|l|l|}
\hline TEMAS Y DEBATES EN LOS ARTíCULOS & $\%$ \\
\hline Crimen organizado, narcotráfico, impunidad y corrupción & $27 \%$ \\
\hline Crisis, economía, finanzas & $19 \%$ \\
\hline Partidos políticos y elecciones & $15 \%$ \\
\hline Gobierno de Felipe Calderón y secretarios de estado & $12 \%$ \\
\hline Política exterior y temas internacionales & $6 \%$ \\
\hline Otros & $21 \%$ \\
\hline
\end{tabular}

Elaboración propia.

Existe menos de un $2 \%$ de artículos en los cuales los temas abordados no representan ningún problema de importancia nacional y sólo se enfocan a temas irrelevantes como quien escribe del sol y la playa.

\section{Editoriales}

A través del editorial el medio de comunicación, la empresa (persona moral) y de hecho el dueño, manifiesta su conciencia respecto a la realidad local, nacional o internacional. Como lo expresa José Luis Martínez Albertos "el editorial es la manifestación de la conciencia del periódico acerca de un problema particular, y si el periódico quiere mantener su prestigio y autoridad moral ante el público debe presentar el editorial con esas notas exteriores y formales de dignidad y seriedad lingüística" (1998:369).

Aquí es importante destacar que el papel de un periódico como productor de texto de opinión está siendo valorado cada vez más en los tiempos modernos, hasta el punto de que ciertos teóricos de la comunicación afirman que los comentarios son los únicos mensajes 
verdaderamente originales de un periódico (Santamaría Suárez, 2000:61). Tomar posturas definidas significa que los grupos de poder compartan o no nuestra visión y enfrentar los riesgos que esto significa.

El escrito del editorial es un pensamiento razonador que mantiene el papel hegemónico de la prensa como poder o contrapoder, según se perciba por cada estamento social. En la actualidad juega dos papeles fundamentales:

a) Opinión respecto a las noticias que se publican.

b) Proponer temas que constituyen un problema social, político, ético o moral sin que tengan noticias recientes como soporte. Toda fenomenología social puede ser materia argumentativa para un artículo editorial que refleje la posición ideológica del periódico ante toda problemática o cambio estructural.

Como también reflexiona María Jesús Casal Carro en su libro La opinión periodística, el periódico es un máximo representante de las corrientes ideológicas que discurren por las venas del cuerpo social. Por todo ello, el rango del editorial es superior a todos los demás artículos de opinión que aparecen en los diarios. El editorial supone la identificación de la prensa como órgano de opinión y de representación social.

En la teoría periodística se han considerado como funciones periodísticas y sociales del editorial las siguientes: Explicar los hechos, dar antecedentes, predecir el futuro y formular juicios.

En esencia todos los medios de comunicación deben publicar diariamente un editorial manifestando su postura sobre el tema o los temas que consideren más relevantes para la vida social y colectiva. En pocos casos algunos periódicos como The Washington Post han tardado un día o dos para manifestar una postura sobre sucesos como la invasión a Afganistán por parte de Estados Unidos. Esto se presenta cuando el medio de comunicación no tiene los elementos suficientes para definirse.

El medio de comunicación que no editorializa o que no se identifica claramente su editorial, se escuda en las noticias o las firmas de sus columnistas o articulistas sin expresar claramente lo que opina como organización. Evaden su responsabilidad y compromiso social.

Es importante porque todos debemos conocer el mensaje informativo e ideológico que adquirimos diariamente con la elección y compra de uno o varios diarios. Es nuestra 
responsabilidad como receptores y consumidores de ideologías. La manipulación de los espíritus existe y hasta tiene sus propios estudios de "mercado". La libertad y la independencia del que conoce, del que ha sabido y podido formar sus propios criterios, son armas defensivas que neutralizan los posibles efectos de los intereses ocultos que puedan mover a toda empresa ideológica.

De ahí su fuerza influyente cuando el lector busca una orientación sobre lo que está pasando en el mundo: busca que el periódico, la institución ideológica por excelencia, le confirme sus opiniones o que le asista en la duda.

Es necesario que el medio publique una postura clara, directa, explícita de lo que sucede. Esto no exenta al miedo de caer presa de los intereses políticos y económicos que no son propios de la sociedad, sino que obedecen a intereses particulares. La presentación de la agenda setting no sólo se observa en los géneros informativos, sino también en los opinión. Se presentan los temas de relevancia y se ubican los temas que deben ocupar al país o que cierto grupo en el poder desea que lo ocupen.

De los géneros existentes, el editorial constituye la opinión del periódico, radio, televisión o página de Internet respecto a la información que se publica. Las noticias, las entrevistas, las crónicas y los reportajes permiten que el público conozca lo sucedido, pero es el editorial el que le da un sentido a esa realidad y la interpreta bajo la mirada del medio al ciudadano. Con ello se tiene una postura orientadora y con una fuente visible.

Es significativo que sólo dos de los medios analizados, La Jornada y El Universal, presenten un editorial, aunque este último medio no todos los días lo publica. Hay voces que afirman que el editorial del medio se encuentra en la lectura de todas las noticias, es decir, se editorializa a través de la construcción del medio. El editorial es la opinión del medio respecto a las noticias que publica por lo cual resulta inmoral cobijarse detrás de la neutralidad de las noticias.

El Universal publica una sección titulada Opinión en la cual presenta los artículos, columnas y también el editorial. Generalmente este último sólo trata un tema del día, preferentemente nacional y que no representa, en la mayoría de las ocasiones, la jerarquía de la información publicada en las primeras planas.

El periódico Reforma, de presencia nacional y de referencia internacional para la política exterior mexicana, cuentan con una sección de Opinión en la cual se incluyen también artículos y columnas, pero no el editorial. Resulta paradójico que estos medios de 
comunicación, con prestigio entre los consumidores de información y que simbolizan referentes sociales para los grupos de poder, no manifiesten abierta y directamente su postura sobre acontecimientos de relevancia. Aunque su agenda setting que establecen puede dar a conocer la línea del periódico, es importante que lo expresen en ejercicio pleno de su libertad.

En el periódico Milenio, también de referencia nacional e internacional, no se presenta un texto editorial. Este periódico de gran relevancia e impacto político asume una postura cómoda de no definirse. El Financiero, otro medio de comunicación de élite en el país, tampoco publica el editorial. Las columnas aparecen a lo largo de las páginas del periódico y los artículos se ubican en una sección titulada Opinión. Estos medios de comunicación no opinan de manera explícita.

En el caso de La Jornada, sí publica el editorial, en ocasiones dos temas nacionales e internacionales. Las columnas son presentadas a lo largo del periódico y los artículos en la sección Política/Opinión. En el Excélsior, periódico tradicional en la vida pública del país, desde que fue comprado por Grupo Imagen eliminó el Editorial y sólo ha conservado una sección titulada Editorial en la cual aparecen los artículos y columnas.

Es decir, en la prensa mexicana estamos observando un desdeño por el escrito editorial como una forma de no asumir una postura determinada frente acontecimientos trascendentales en el ámbito nacional e internacional.

En los editoriales de La Jornada y El Universal (Cuadro 3) los temas que prevalecen son los de economía, seguidos por los internacionales y posteriormente por los del Crimen organizado.

\section{Cuadro 3}

Temática en el Editorial.

\begin{tabular}{|l|c|}
\hline Temas y debates en el editorial & $\%$ \\
\hline Crimen organizado, narcotráfico, impunidad y corrupción & $16 \%$ \\
\hline Crisis, economía, finanzas & $26 \%$ \\
\hline Partidos políticos y elecciones & $5 \%$ \\
\hline Gobierno de Felipe Calderón y secretarios de estado & $15 \%$ \\
\hline
\end{tabular}




\begin{tabular}{|l|c|}
\hline Política exterior y temas internacionales & $22 \%$ \\
\hline Otros & $16 \%$ \\
\hline
\end{tabular}

Elaboración propia.

\section{Estilo:}

Consideramos que el estilo es la belleza estética en todo escrito. El lector lee una columna, artículo, editorial, no sólo para conocer una postura, sino para deleitarse con la espléndida construcción del texto. Aunque más del $70 \%$ de los textos analizados presenta un estilo formal hay quien utiliza el estilo humorístico, sarcástico.

Consideremos textos como la columna de Catón que todos los días publica con un estilo humorístico, el estilo formal de Jorge Fernández Menéndez, la manera de enumerar de Carlos Ramírez o el estilo ligero de Germán Dehesa. La columna es el género que se utiliza para hacer un análisis más informal de los asuntos. Los articulistas por el contrario emplean en su mayoría un estilo más profundo y formal para cada uno de sus textos.

Los artículos concebidos como entretenimiento literario tienen muy poca presencia en las páginas de opinión y políticas de los diarios. El columnista y articulista está definido como un buen escritor y algunos utilizan un estilo ameno.

Interactividad. Aún cuando más del $35 \%$ de los articulistas y columnistas publican su correo electrónico, su blog o su página personal, lamentablemente menos del $4 \%$ retroalimenta al lector. Esto ejemplifica que a los constructores de opinión pública no les interesa lo que opinan los lectores o los ciudadanos en general. Lamentablemente en el ejercicio que realizamos escribimos más de cinco correos a cada periodista, correos que no fueron contestados.

\section{La mujer en la opinión pública:}

Aquí es relevante y significativo el hecho de que en el artículo la presencia de la mujer es sólo del $16 \%$ y en la columna del 14\%. Si los géneros de opinión tienen la aportación social de presentar una visión es extraño e incorrecto que la visión, el análisis y la propuesta sea en su mayoría desde el ángulo del hombre y no de la mujer.

Si analizamos el nivel de argumentación, la capacidad de análisis y la presentación de tesis, los artículos y las columnas de las mujeres se encuentran en un nivel similar al que tienen los 
textos escritos por hombres. Sólo la presencia es lo que lo distingue, pero no el nivel del pensamiento.

Las mujeres están presentes en todas las profesiones y concretamente en el periodismo su número ha igualado al de los hombres durante los últimos 20 años del siglo XX. Pero, para influir, para formar opinión, las mujeres no son elegidas por los directores y dueños de los periódicos y medios audiovisuales.

\section{Conclusiones}

Los medios de comunicación son espejo de la sociedad en la que viven a la vez que inductores de estados de opinión en una retroalimentación que no hace de la prensa un cuarto poder precisamente, sino un altavoz representativo e incluso anunciador de realidades futuras, por ello es importante conocer qué piensa el medio que se consume y quienes allí opinan.

La influencia de los géneros de opinión se manifiesta cuando llegan a un grupo de lectores que tienen poder de decisión, libertad de actuación y claridad ideológica. Para ellos, estos textos se escriben muchas veces buscando generar polémica. Esa es la razón de que puedan ser capaces en ocasiones de desencadenar hechos en la vida política, económica y social de un país.

La política de opinión está presente en todo el periódico. El artículo editorial es la voz que juzga, reclama, aprueba, ensalza o rechaza hechos y personajes con una base ideológica indiscutible, por lo que constituye un verdadero parlamento diario de esos influyentes representantes sociales que son los periódicos y periodistas. Representantes no electos, aunque sí sintetizadores de posiciones ideológicas mayoritarias.

En este camino a un país democrático y con justicia, los medios de comunicación deben jugar un papel plenamente establecido, no parcialmente, sino cumpliendo con sus dos grandes deberes que son la de informar y la orientar para lograr uno de los más grandes objetivos que es el de ensanchar las libertades del hombre. 


\section{Bibliografía}

- Buendía, Manuel (1996). Ejercicio periodístico. México: Ed. Fundación Manuel Buendía.

- Benito, Ángel (2001). Diccionario de periodismo. Madrid: Ed. CESMA.

- Casals Carro, María Jesús (2005). Periodismo y sentido de la realidad. Teoría y análisis de la narrativa periodística. Madrid: Ed. Fragua.

- Martínez Alberto, José Luis (1998). Curso General de Redacción Periodística. España: Ed. Paraninfo.

- (1998) Manual de estilo. México: Ed. Proceso.

- Santamaría Suárez, Luisa y Casals Carro, María Jesús (2000). La opinión periodística. Madrid: Ed. Fragua.

- Periódicos de diciembre 2008, enero, febrero y marzo del 2009 de: El Universal, Milenio, Reforma, Excelsior, La Jornada, El Financiero.

Proyecto de investigación apoyado por el Fondo de Apoyo a la Investigación de la Universidad Autónoma de San Luis Potosí, México.

\section{Forma de citar este artículo en bibliografías}

Navarro Zamora, L. (2010): "La opinión publicada en la prensa de México (Columna, artículo y editorial)", en Revista PANGEA, 1, páginas 160 a 176. Red Académica Iberoamericana de Comunicación. Recuperado el _ de _ de 2 _ de: http://revistapangea.org/2010/12/05/01-01-108/ 